\title{
MODIFICATION OF PLANETARY ATMOSPHERES BY MATERIAL FROM THE RINGS
}

\author{
S. K. Atreya
}

The University of Michigan, Department of Atmospheric and Ocean Science, Ann Arbor, MI 48109-2143, U.S.A.

\author{
ABSTRACT
}

The atmospheres and ionospheres of ringed planets can be, and perhaps are, modified by the injection of gaseous neutral and ionized species, and dust of ring origin. Although no direct evidence for such interaction exists, many of the unresol ved characteristics of planetary composition, thermal structure and ionosphere would be understood if the rings supplied certain materials to their parent planets.

\section{INTRODUCTION}

The definition of 'rings' in this paper has been stretched somewhat to include the 'toroidal gas/plasma ring' in the orbit of Io around Jupiter. Otherwise, the extensive ring system of Saturn, diffuse ring of Jupiter, and the recently discovered rings of Uranus are the focus of bulk of the discussion. Neptune too may possess rings, and their influence is considered as part of a general theme on the tropospheric/stratospheric thermal structure. The rings of Saturn are dirty snow/ice balls, i.e., they are composed of chunks of rocks (silicates) and ice or snow. Jupiter's ring, on the other hand, is made up of micron to sub-micron size dust particles. The Io-torus is composed of sulfur and oxygen ions whose source lies presumably in the volcanoes of Io. The rings of Uranus are believed to be mostly dark material (silicates?) due to their low reflectivity. There is only a scant speculation about the existence of ring/s around Neptune. Considering the intense and extensive magnetospheres around these planets (excluding perhaps Neptune), and the probability of micrometeoritic bombardment on the rings, one can envision the removal, and eventual migration of material from the rings to the planets. For the present

discussion, it has been assumed 'a-priori' that material can be removed from the rings by one of the many competing processes, such as energetic charged particle sputtering, micrometeoroid impact or photosputtering. Once removed, the material diffuses in toward the planet and interacts with its atmosphere or ionosphere. It is this latter aspect of interaction that forms the basis for the remainder of this paper. In particular, the following issues are discussed.

\section{Thermal Structure}

(a) Tropospheric/stratospheric temperature and dust/aerosols.

(b) Thermospheric/exospheric temperature and auroral energy deposition by Iotorus ions.

\section{Neutral Chemistry}

(a) H-production due to particle impact of $\mathrm{H}_{2}$ on Jupiter.

(b) Co production due to oxygen injection at Jupiter.

(c) Water in Saturn and Jupiter atmospheres. 


\section{Ionospheric Structure}

(a) Ion loss on $\mathrm{H}_{2}\left(v^{\prime} \geq 4\right)$ at Jupiter due to energetic particle injection.

(b) Ion loss at Saturn due to injection of $\mathrm{H}_{2} \mathrm{O}, \mathrm{OH}$, or $\mathrm{O}$.

(c) Sporadic E-type layering due to injection of metallic ions (such as $\mathrm{Na}^{+}$) at Jupiter.

THERMAL STRUCTURE

\section{(a) Tropospheric/Stratospheric Temperature}

In the homospheres of the major planets, LTE prevails for pressures $\geq 1 \emptyset \mu \mathrm{b}$. Radiativeconvective equilibrium models are valid in the troposphere ( $\geqslant 0.5 \mathrm{bar}$ ). Due to the large thermal capacity of $\mathrm{He}+\mathrm{H}_{2}$, radiative transport is dominated by these gases in the troposphere, although weaker bands of $\mathrm{CH}_{4}$ and dust or aerosols are sometimes needed for absorbing the solar flux. Heating in the stratosphere is due mainly to the absorption in the $\nu_{3}$-band of $\mathrm{CH}_{4}$ at $3.3 \mu \mathrm{m}$, with subsequent re-radiation in the $v_{4}$ band of $\mathrm{CH}_{4}$ at $7.8 \mu \mathrm{m}$. Most RT-equilibrium models require presence of some type of aerosol or dust in the stratosphere to explain the observed heating, and the methane emission at $7.8 \mu \mathrm{m}$. The source of aerosols has been generaily assumed to be photochemical haze produced on condensation of some photolysis product. On Jupiter, photolysis of $\mathrm{NH}_{3}$ produces hydrazine $\left(\mathrm{N}_{2} \mathrm{H}_{4}\right)$, some of it is likely to condense. The condensation, however occurs in the troposphere ( $F$ ig. 1, $/ \Lambda$. The same is true for Saturn. The situation is even more severe at Uranus. Nearly $15 \%$ of the solar insolation must be absorbed by aerosol or dust at Uranus, and about $5 \%$ at Neptune $/ 2 \%$ The requirement of smaller solar insolation absorption by dust/aerosols at Neptune is due to the larger absorption by $\mathrm{CH}_{4}$ which is supersaturated in the stratosphere. Perhaps, photochemical haze formed on photolysis of $\mathrm{CH}_{4}$ Can result in the stratospheric aerosols needed on Uranus and Neptune (Fig. $2, / 3 /$.

From the above discussion, it appears that at least on Jupiter and Saturn, the aerosol or dust needed in the RT equilibrium models must be supplied from outside the planet. An obvious candidate is always meteoritic infall. Another possibility is dust particles whose origin is in the rings. At Jupiter, this is not a far-fetched possibility.

The main band of the Jovian ring begins at around $1.72 \mathrm{R}_{\mathrm{J}}\left(1 \mathrm{R}_{\mathrm{J}}=71,400-\mathrm{km}\right)$ and extends quite a ways to the planet. The small particles of the Jovian ring tend to make it unstable due to Poynting Robertson effect, plasma drag, meteoritic bombardment, or charged particle impact. The Jovian ring, therefore must be continually replenished, if it is to be a long-lived phenomena. Pulverizing of small debris in the vicinity of Jupiter by tidal forces or meteoroid impact can produce the fine material of the Jovian ring. Another possibility is that the material from Io plasma-torus forms a gravitationally stable ring around Jupiter after it diffuses away from the torus. There is plenty of fine dust available in the Saturn ring system also, particularly in the $E$ and $F$ rings, and that could also potentially be available for diffusion into the atmosphere.

\section{(b) Thermospheric/txospheric Temperature}

Both Jupiter and Saturn have relatively high exospheric temperatures. Jupiter's approaches $11 \emptyset \emptyset \pm 2 \varnothing \emptyset-\mathrm{K} / 5 /$, while Saturn's lies between 425 and $8 \emptyset \emptyset-\mathrm{K} / 6,7 /$. Solutions of simple one dimensional heat conduction equation show that one would need approximately $0.3 \mathrm{erg} \mathrm{cm} \mathrm{c}^{-2} \mathrm{~s}^{-1}$ of energy flux in the equatorial and midlatitude regions of Jupiter to account for the observed high exospheric temperatures $/ 5 \%$ Approximately $2.8 \pm 1-\mathrm{kR}$ of non-auroral $\mathrm{H}_{2}$-Lyman and werner band emission intensity was measured by Voyager on the dayside of Jupiter $/ 8 \%$. This intensity of the $\mathrm{H}_{2}$ bands implies a soft electron energy flux of $\sim \emptyset .3$ erg $\mathrm{cm}^{-2} \mathrm{~s}$ - enough to sustain the observed exospheric temperature. on the other hand, the nightside non-auroral $\mathrm{H}_{2}$ intensity drops to virtually zero, thus resulting in no energy input on the nightside. One must therefore seek another mechanism for supplying planetwide a relatively large energy flux for maintaining the high exospheric temperatures at Jupiter. The solution is most likely auroral energy input. 

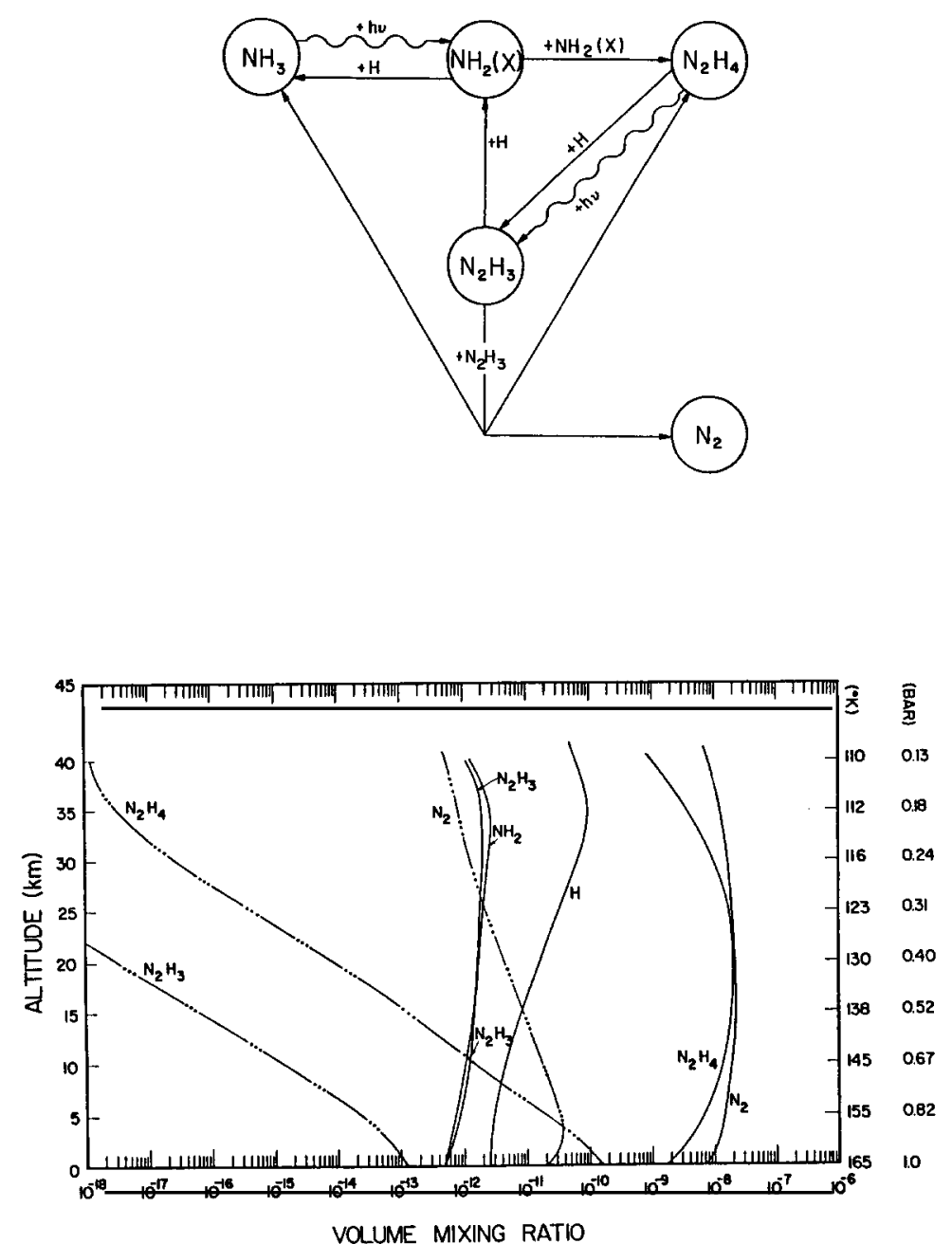

Fig. la (top). $\mathrm{NH}_{3}$ photochemical scheme for Jupiter and Saturn /4/. Fig. 1b (bottom). Distribution of $\mathrm{NH}_{3}$ photochemical products on Jupiter, with (-....---) and without $(\longrightarrow$ condensation of $\mathrm{N}_{2} \mathrm{H}_{4}$. Condensation of $\mathrm{N}_{2} \mathrm{H}_{4}$ would occur throughout the troposphere, however the density of aerosol would be greatest between 0.5 and 1 bar $/ 1$.

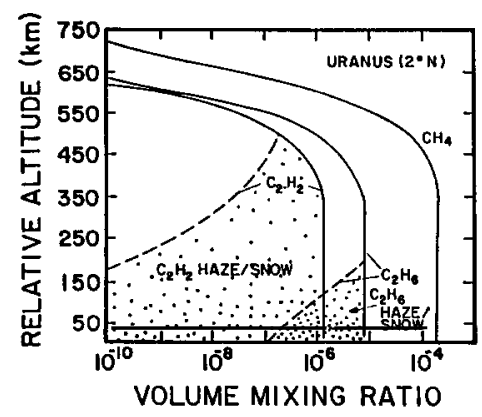

Fig. 2. Aerosol formation due to photolysis of $\mathrm{CH}_{4}$ on Uranus $/ 3 /$. Broken lines are saturation mixing ratios. 
Voyager 1 measured nearly $60-80-\mathrm{kR}$ intensity in the Lyman and werner bands of $\mathrm{H}_{2}$ in the auroral region of Jupiter. The auroral emissions were detected in the region where Io plasma torus magnetically mapped on to Jupiter. To explain the $\mathrm{H}_{2}$ band intensity, a power input of $1.3 \times 10^{13} \mathrm{~W}$ is required. If this auroral power could be spread uniformly over the entire planet -- say by thermospheric winds -- it would amount to a globally averaged energy flux of $0.4 \mathrm{erg} \mathrm{cm} \mathrm{c}^{-1}$. This latter value is almost adequate for heating the exosphere of Jupiter to the observed temperature. How is the auroral power supplied? One possibility is that the energy is supplied by Io plasma torus electrons which are locally heated by the sulfur and oxygen ions accelerated to corotation velocities. The corotation velocity at $6 \mathrm{R}_{\mathrm{J}}$ is $\sim 56-\mathrm{km} \mathrm{s}^{-1}$ which corresponds to $26 \emptyset-\mathrm{eV}$ for an oxygen and $52 \emptyset-\mathrm{eV}$ for a sulfur iop. Thus, a power input of $\sim 10^{1} \mathrm{~W}$ would imply ion production rate in excess of $2 \times 10^{29} \mathrm{~s}^{-1}$. The torus however contains only $5 \times 10^{34}$ ions $/ 9 \%$ with ion diffusion lifetimes on the order of $1 \varnothing$ to $60 \emptyset$ days $/ \varnothing /$, the available source of ions at lo lies between $10^{27}$ and $5 \times 1 \emptyset^{28}$ ions $\mathrm{s}^{-1}$. The nominal value of diffusion lifetime is $10 \emptyset$ days, corresponding ion production rate is $5 \times 10^{27}$ ions $s^{-1}$. Thus, the available ion production rate is much lower than required to explain the total auroral power input at Jupiter.

An alternate source proposed is the precipitation directly of the energetic sulfur and oxygen ions of the Io torus (rather than torus electrons) into the Jovian atmosphere $/ 11 /$. The analysis of Voyager Cosmic Ray Subsystem observations of 1 to $20-\mathrm{MeV} /$ nuc oxygen and sulfur ions indicates positive radial gradient between 6 and $17 R_{J}$ for the oxygen ions. This implies inwardly diffusing ions. Gehrels and Stone $/ 11 /$ calculate, on combining the CRS data with the data of Voyager plasma observations, that ions with magnetic moments of $27 \varnothing-\mathrm{MeV} / \mathrm{nuc}-\mathrm{G}$ deliver $4 \times 1 \emptyset^{12}$ watts of power above the homopause of Jupiter (Fig. 3 ).

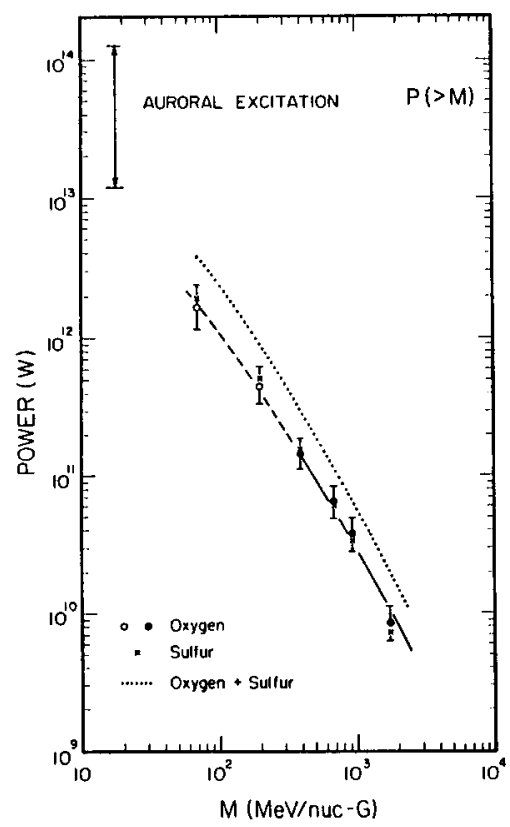

Fig. 3. The total power delivered by $O$ and $S$ ions with magnetic moments greater than $M$ $11 /$.

They also calculate that the needed auroral power of $\sim 1 \theta^{13} \mathrm{~W}$ can be supplied by precipitation of $10^{26} \mathrm{O}$ and $\mathrm{S}$ ions with lower magnetic moments, 10 to $30-\mathrm{MeV} / \mathrm{nuc}-\mathrm{G}$ (or $\geq 35$ to $10 \emptyset-\mathrm{keV} /$ nuc at $\left.10 \mathrm{R}_{\mathrm{J}}\right)$. Thus torus ions are capable of delivering the power needed to drive the aurora at Jupiter. The ions also deposit their energy at an altitude ( 50ø$\mathrm{km}$ where $\left.\left[\mathrm{H}_{2}\right] \approx 10^{19} \mathrm{~cm}^{-2}\right)$ where they are most effective in producing the aurora $\left(\mathrm{H}_{2}\right.$ bands produced below the homopause will be absorbed by $\mathrm{CH}_{4}$ ) and causing local heating, At Saturn the required energy for exospheric heating is less than $0.1 \mathrm{erg} \mathrm{cm}^{-2} \mathrm{~s}-1$ and is easily available in the auroral power input of $2 \times 10^{11} \mathrm{~W}$ in the high latitudes. When spread over the entire planet, however, the auroral power amounts to $\sim \emptyset . \varnothing 1 \mathrm{erg} \mathrm{cm} \mathrm{cm}^{-2} \mathrm{~s}^{-1}$, which is clearly inadequate for the observed exospheric temperatures. The Saturn aurora differs from the one on Jupiter in the sense that it is a magnetotail type aurora. Joule heating might play a major role in the thermospheric/exospheric heating on saturn, but rings do not participate in this process. 
Neutral Chemistry

Voyager measured 13 to $14-\mathrm{kR}$ of non-auroral Ly $\alpha$ intensity at Jupiter. Resonance scattering of solar Lyman-alpha photons is responsible for the excitation of this radiation. To produce 13 to $14-\mathrm{kR}$, one requires nearly $1 \varnothing$ times more atomic hydrogen than can be produced in the $\mathrm{CH}_{4}$ photochemistry and the ionosphere of Jupiter. The excess hydrogen can be produced by charged particle dissociation of $\mathrm{H}_{2}$. The origin of these charged particles, as discussed previously, lies in the Io-plasma torus. Once produced in the auroral region, the hydrogen atoms can be spread over the entire planet by thermospheric transport. No such requirement for explaining the non-auroral Ly $\alpha$ emission at Saturn exists. Adequate hydrogen is produced by conventional means (photochemistry), and none other is required. It is just as well, since large production of $\mathrm{H}$ atoms in the auroral regions of Saturn does not occur.

Carbon monoxide detected in the atmosphere of Jupiter poses a challenge. $C O$ is thermochemically stable at $110 \emptyset \mathrm{K}$ in the deep troposphere of Jupiter, where it is produced on oxidation of $\mathrm{CH}_{4}$. In order for it to be detected in the upper atmosphere, it must either be convected from deep troposphere, or somehow supplied from outside the planet. Deciding between the two possibilities is rendered impossible by the large disagreement in rotational temperatures of the two available sets of data. Beer and Taylor $/ 2$ / quote a value of $125 \pm 25 \mathrm{~K}$, while Larson et al. $/ 13 / \mathrm{give} 150-300 \mathrm{~K}$. Prinn and Barshay $/ 14 /$ have argued for strong vertical mixing with an eddy diffusion coefficient of $2 \times 1 \emptyset^{8} \mathrm{~cm}^{2} \mathrm{~s}^{-1}$ to mix $C O$ to the upper atmosphere. Another possibility, however, is extraplanetary oxygen. For Jupiter, a likely source is the oxygen from Io plasma torus, as discussed earlier. Oxygen atoms react readily with methyl $\left(\mathrm{CH}_{3}\right)$ radicals which are produced in the $\mathrm{OH}_{4}$ photochemistry. The resulting formaldehyde undergoes numerous intermediate reactions, producing eventually $\mathrm{CO}$. Small amounts of $\mathrm{CO}$ are also produced on reaction of $\mathrm{O}$ with $\mathrm{CH}_{2}$, which is also produced on photodissociation of $\mathrm{CH}_{4^{*}}$. A complete chemical scheme is given below.

TABLE 1 CO Chemistry

$$
\begin{array}{r}
\mathrm{O}+\mathrm{OH}_{3} \rightarrow \mathrm{HCHO}+\mathrm{H} \\
\mathrm{HCHO}+\mathrm{O} \rightarrow \mathrm{HCO}+\mathrm{OH} \\
\mathrm{HCO}+\mathrm{O} \rightarrow \mathrm{OH}+\mathrm{CO} \\
\mathrm{HCO}+\mathrm{H} \rightarrow \mathrm{H}+\mathrm{CO}_{2} \\
\mathrm{O}+\mathrm{CH}_{2} \rightarrow \mathrm{H}_{2}+\mathrm{CO}
\end{array}
$$

The total flux of oxygen atoms entering Jupiter is on the grder of (6.3 to 5) $\times 1 \emptyset^{7} \mathrm{~cm}^{-2}$ $\mathrm{s}^{-1} / 15 /$ which is sufficient for producing the observed $10^{-9}$ volume mixing ratio of $\mathrm{co}$. To be sure, ablation of carbonaceous chrondrific meteorites in the atmosphere of Jupiter can also supply an $\mathrm{H}_{2} \mathrm{O}$ flux of $10^{7}$ to $2 \times 10^{9} \mathrm{~cm}^{-2} \mathrm{~s}^{-1} / 16 /$. Such large fluxes of $\mathrm{O}$ or $\mathrm{H}_{2} \mathrm{O}$ at Saturn do not exist, and $\mathrm{CO}$ has not been detected in Saturn's atmosphere.

Introduction of oxygen atoms, or oxygen bearing molecules, such as $\mathrm{H}_{2} \mathrm{O}$ into the reducing atmospheres of the major planets has the consequence of altering the photochemical reactions in the middle atmosphere. No direct evidence of it has so far been seen, however entry probe mass spectrometer measurements, such as those planned on Galileo will be highly revealing.

\section{IONOSPHERIC STRUCTURE}

\section{(a) Ion Loss on $\mathrm{H}_{2}\left(v^{\prime} \geq 4\right)$ at Jupiter}

There is at least a factor of 10 discrepancy between the observed (by Voyager) and calculated peak electron concentrations both at Jupiter and Saturn $/ 17,18 \%$. Since the data below $2009-\mathrm{km}$ have not been analyzed, it is not apparent if the discrepancy is real, since the main peak in electron concentration at Jupiter may well 1 ie deeper in the atmosphere. Pioneer $1 \varnothing$ and 11 did measure several 'peaks' or layers in ionization. If the Voyager data do indicate the peak to be at $\sim 2000-\mathrm{km}$, as is presently the situation, then the theoretical models require modification. At least for the high latitude 
ionospheres, the answer may lie in the material (charged particles) transported form the Io-torus.

The major ion in the models of the ionosphere of Jupiter is $\mathrm{H}^{+}$. It has a lifetime of 10 to 100 days around the peak in electron concentration. Once produced, it is not likely to be removed, unless it is converted to a molecular ion. Atreya et al. $19 /$ proposed conversion of $\mathrm{H}^{+}$to $\mathrm{H}_{2}{ }^{+}$, and subsequentl $\mathrm{y} \mathrm{H}_{3}{ }^{+}$. This can be accomplished if $\mathrm{H}_{2}$ molecules were vibrationally excited (to be exact, in the 4th or higher vibrational state). The scheme is as shown below.

$\mathrm{H}^{+}+\mathrm{H}_{2}\left(\mathrm{~V}^{\prime} \geq 4\right) \rightarrow \mathrm{H}_{2}^{+}+\mathrm{H}$

followed by

$\mathrm{H}_{2}^{+}+\mathrm{H}_{2} \rightarrow \mathrm{H}_{3}^{+}+\mathrm{H}$

and

$\mathrm{H}_{3}^{+}+\mathrm{e} \rightarrow \mathrm{H}_{2}+\mathrm{H}$

or

$\rightarrow \mathrm{H}+\mathrm{H}+\mathrm{H}$

It has been demonstrated by McConnell et al. $/ 20 /$ and Waite et al. $/ 21 /$ that the theoretical models can be reconciled with the data by employing the above scheme (Fig. 4).

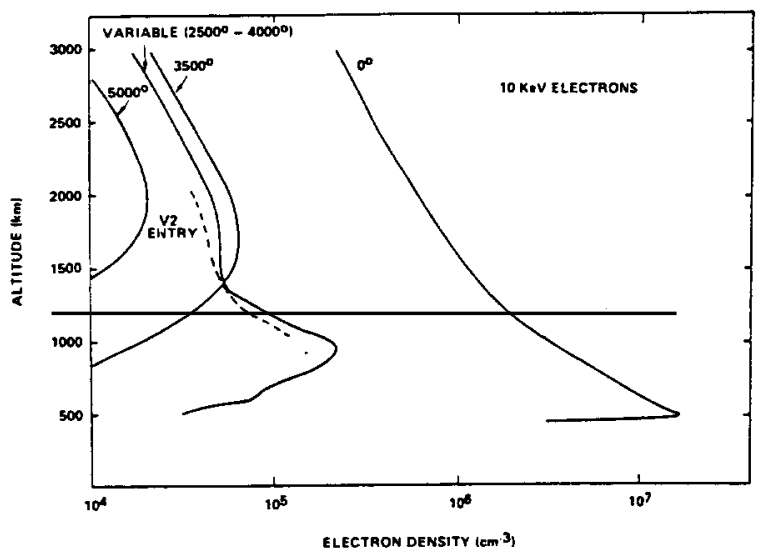

Fig. 4. Comparison of modeled and measured auroral ionospheres at Jupiter. The effect of vibrational temperature (hence vibrational population of $\mathrm{H}_{2}\left(\mathrm{v}^{\prime} \geq 4\right)$ on the ionospheric profile is shown for various temperatures $/ 21 \%$.

The energy for the vibrational excitation of $\mathrm{H}_{2}$ is available in the auroral power $/ 21 /$. As discussed earlier, the energy is delivered most likely by the sulfur and oxygen ions of the Io-torus origin. The Jovian ionosphere problem is not entirely resolved, however, as enough energy is not available in the non-auroral regions to produce the required population of $\mathrm{H}_{2}\left(\mathrm{v}^{\prime} \geq 4\right)$.

\section{(b) Ion Loss at Saturn}

Although large ion transport from the rings to Saturn's atmosphere is unlikely, there is a large reservoir of $\mathrm{H}_{2} \mathrm{O}$ there. Voyager UV spectrometer detected $400 \mathrm{R}$ of Ly $\alpha$ above the ring plane (Fig. $5 / 22 \mathrm{~N}$, indicating presence of at least a hydrogen atmosphere there. The process that produces the H-atmosphere above the rings can also produce oxygen atams, and $\mathrm{H}_{2} \mathrm{O}$ molecules. Once removed from the rings these atoms and molecules would diffuse inward and modify the atmosphere and ionosphere of Saturn. First, mechanisms for producing the $\mathrm{H}$-atmosphere around the rings are briefly discussed, and then the effect of introducing water molecules into Saturn is discussed. 


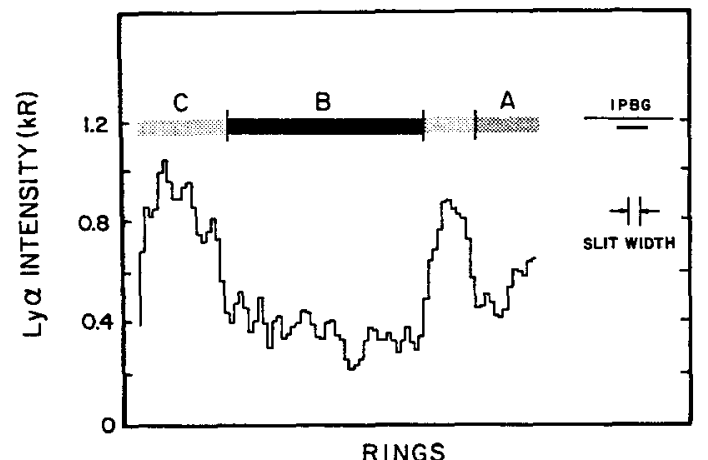

Fig. 5. H-atmosphere in the ring plane. To avoid confusion with interplanetary Lya, only data in the vicinity of the B-ring should be considered. The slant optical thickness of the dark B-ring was 3, and the sunlit and dark sides of the B-ring had almost identical brightnesses $/ 22 \%$.

The Voyager UVS observations of Ly $\alpha$ would imply $\mathrm{H}$ density of $\sim 600_{33} \mathrm{am}^{-3}$, and for a uniformly distributed cloud of cross sectional radius $1 R_{S}, 5 \times 10^{33} \mathrm{H}$ atoms in the cloud 122\% Photosputtering of the rings produces less than one tenths the amount of $\mathrm{H}$ needed to explain the Ly $\alpha$ observations $/ 23 \%$. Furthermore, this mechanism should be ineffective when the rings are edge-on to the sun -- which is what they were at the time of voyager encounter. Ip /24/ suggests neutralization of ionospheric $\mathrm{H}^{+}$on the ring surfaces. Production of an $\mathrm{H}$-atmosphere around the rings by interplanetary meteoroid impact has been proposed by Blamont $/ 25 /$ and Morfill et al. $/ 26 /$. Another mechanism proposed by Cheng et al. $/ 27 /$ is the magnetospheric charged particle sputtering of the ring material. The analysis of low energy charged particle data from Voyager by the latter authors indicates that the gradient in ion phase space densities is such that particle losses occur mainly between 4.5 and $8-R_{S}$. That is, if particle sputtering is important, it must occur on the E-ring, and the moons Tethys and Dione -- not the outer edge of A-ring. For a reasonable range of ion radial diffusion coefficient $\left(D_{1}=D_{0} L^{n}, n=3\right.$ to 10$)$, they find the total ion loss rate of between $3 \times 10^{22} \mathrm{~s}^{-1}$ to $4 \times 10^{24} \mathrm{~s}^{-1}$. The magnetospheric ions in question are protons of energies $25 \emptyset-\mathrm{keV}$. Sputtering of water ice on the E-ring would produce one $\mathrm{H}_{2} \mathrm{O}$ molecule for each proton impact. Thus, the $\mathrm{H}_{2} \mathrm{O}$ production rate is $3 \mathrm{x}$ $10^{22}$ to $4 \times 10^{24} \mathrm{~s}^{-1}$. Photodissociation of $\mathrm{H}_{2} \mathrm{O}$ produces $\mathrm{H}$ atoms which have a lifetime of $3 \times 16^{5}-\mathrm{sec}$ at Saturn. Thus the maximum total H-atoms that can be produced above the ring plane would be $10^{30}$ atoms $\left(4 \times 10^{24} \mathrm{~s}^{-1} \times 3 \times 10^{5} \mathrm{~s}\right)$, which is considerably lower than the $5 \times 10^{33} \mathrm{H}$-atoms required to explain the Ly $\alpha$ observations. Therefore, al though the energetic particle sputtering does not seem to produce the required $\mathrm{H}$-density around the rings, it does produce a certain flux of $\mathrm{H}_{2} \mathrm{O}$. If one imagines that the mechanism producing $\mathrm{H}$-atmosphere around the rings (such as meteoritic impact) also results in the $\mathrm{H}_{2} \mathrm{O}$ sputtering, then the flux of $\mathrm{H}_{2} \mathrm{O}$ would be 1000 times greater. The lifetime of $\mathrm{H}_{2} \mathrm{O}$ against EUV or electron impact dissociation at Saturn is $\sim 10 \emptyset$ days. One can therefore envision a relatively large flux of $\mathrm{H}_{2} \mathrm{O}$ arriving at Saturn's atmosphere. The value can reach $\sim 10^{3} \mathrm{~cm}^{-3} \mathrm{H}_{2} \mathrm{O}$ molecules.

As mentioned earlier, theoretical models of the ionosphere of Saturn also yield electron concentrations too high in comparison with measurements. Unlike Jupiter, the vibrational population of $\mathrm{H}_{2}$, even in the auroral regions, is not high enough to provide a sink to the major ion, $\mathrm{H}^{+}$. On the other hand, if $\mathrm{H}_{2} \mathrm{O}$ could be injected into the atmosphere, there is a good possibility of reconciling theory with the data. The ensuing chemistry is presented below $/ 28 /$.

$$
\begin{array}{lll}
\mathrm{H}_{2} \mathrm{O}+\mathrm{hv} & \rightarrow \mathrm{H}+\mathrm{OH} \\
\mathrm{H}^{+}+\mathrm{OH} & \rightarrow & \mathrm{OH}^{+}+\mathrm{H} \\
\mathrm{OH}^{+}+\mathrm{H}_{2} & \rightarrow & \mathrm{H}_{2} \mathrm{O}^{+}+\mathrm{H} \\
\mathrm{H}_{2} \mathrm{O}^{+}+\mathrm{H}_{2} & \rightarrow & \mathrm{H}_{3} \mathrm{O}^{+}+\mathrm{H} \\
\mathrm{H}_{3} \mathrm{O}^{+}+\mathrm{nH}_{2} \mathrm{O} \rightarrow & \mathrm{H}_{3} \mathrm{O}^{+}\left(\mathrm{H}_{2} \mathrm{O}\right)
\end{array}
$$


$\begin{array}{lll}\underset{\mathrm{Ond}}{*}+\mathrm{H}_{2} & \rightarrow & \mathrm{H}_{2} \mathrm{O}+\mathrm{H} \\ \mathrm{H}^{+}+\mathrm{H}_{2} \mathrm{O} & \rightarrow & \mathrm{H}_{2} \mathrm{O}^{+}+\mathrm{H}\end{array}$

etc.

$\mathrm{OH}$ (ground state) produced in the photolysis of $\mathrm{H}_{2} \mathrm{O}$ charge exchanges readily with $\mathrm{H}^{+}$. Subsequent reactions with atmospheric $\mathrm{H}$ and $\mathrm{H}_{2}$ produce molecular ions such as $\mathrm{H}_{2} \mathrm{O}^{+}, \mathrm{H}_{3} \mathrm{O}^{+}$, and even cluster ions, $\mathrm{H}_{3} \mathrm{O}^{+}\left(\mathrm{H}_{2} \mathrm{O}\right) \mathrm{n}^{*}$ Excited state $\mathrm{OH}$ (produced in photolysis of $\mathrm{H}_{2} \mathrm{O}$ also) reacts with $\mathrm{H}_{2}$ to produce $\mathrm{H}_{2} \mathrm{O}{ }^{2} \mathrm{H}^{+n^{*}}$ can also directly charge exchange with $\mathrm{H}_{2} \mathrm{O}$. In all above reactions, the long lived major ion $\mathrm{H}^{+}$has been converted to short lived molecular ions. Indeed Chen $/ 29 /$ and Connerney and waite $/ 30 /$ have shown that the observed ionospheric profile at Saturn can be interpreted theoretically, if the atmosphere contained $\mathrm{H}_{2} \mathrm{O}$ molecules. Chen's model would require a vertically constant density of $\mathrm{OH}$ (or $\mathrm{H}_{2} \mathrm{O}$ ) of $10^{4} \mathrm{~cm}^{-3}$ (see $\mathrm{Fig.} \mathrm{6),} \mathrm{which} \mathrm{is} \mathrm{about} \mathrm{a} \mathrm{factor} \mathrm{of} 10$ greater than ring sputtering processes are likely to produce. Perhaps, water from meteorites entering the atmosphere could supply the rest.

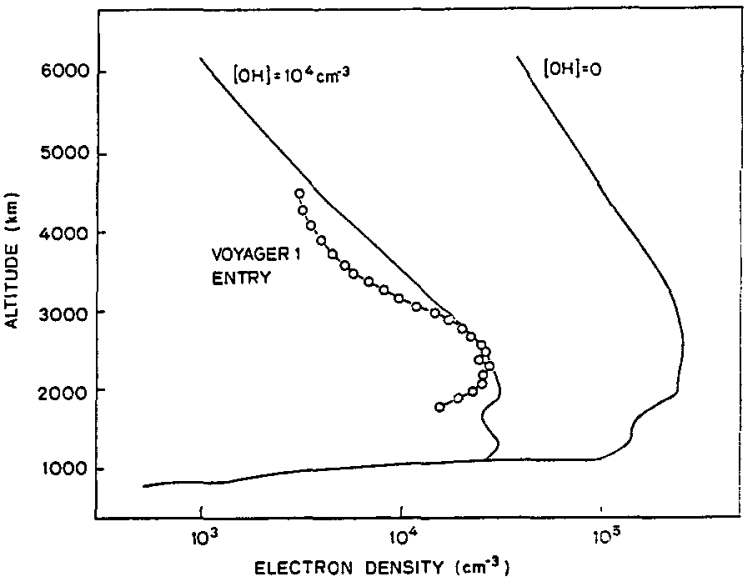

Fig. 6. The effect of $\mathrm{OH}$ in the ionospheric models of Jupiter, and comparison with Voyager 1 measurements $/ 29 \%$

It should be emphasized that except for a not too convincing

interpretation of a set of observations done at $\sim 1600 \mathrm{~A}$ with IUE $/ 31 /$, there is no evidence for the presence of water vapor in Saturn's upper atmosphere. Voyager UVS data are extensive, they include airglow and absorption measurements (solar and stel lar occultations) done between 506 and $1706 \AA$ with a nominal resolution of $10 \AA$. They have not so far revealed any signatures of water vapor in the atmosphere. Perhaps the density is too low for detection.

\section{(c) Sporadic E-Type Layering in Jupiter's Atmosphere}

The Pioneer radio occultation measurements of the ionosphere of Jupiter reveal numerous layers (Fig. 7).

Such sharp ledges in ionospheric profile are reminiscent of sporadic E-type layering in the terrestrial ionosphere. In the midlatitudes, such behavior is the result of layering of long-lived metallic ions due to electric fields produced by wind shear. The Io-torus is a source of metallic ions such as $\mathrm{Na}$ and $\mathrm{K}$. Once ionized (by EUV - or electron impact), these ions can enter the Jovian atmosphere along magnetic field lines connecting Io-torus to Jupiter. The efficiency of such a process is not great, only a fraction of the ions would be able to make it to the atmosphere due to Jupiter's centrifugal acceleration. There is, however, evidence of inward diffusion of sulfur and oxygen ions (as discussed earlier), therefore transport of sodium and other metallic ions should not pose a formidable problem either. Once in the ionosphere, the lifetime of metallic ions, such as sodium, is large ( $1 \emptyset \emptyset$ days). They should result in sporadic E-type layers $132 \%$ Another obvious source of metallic ions is meteoritic influx. 


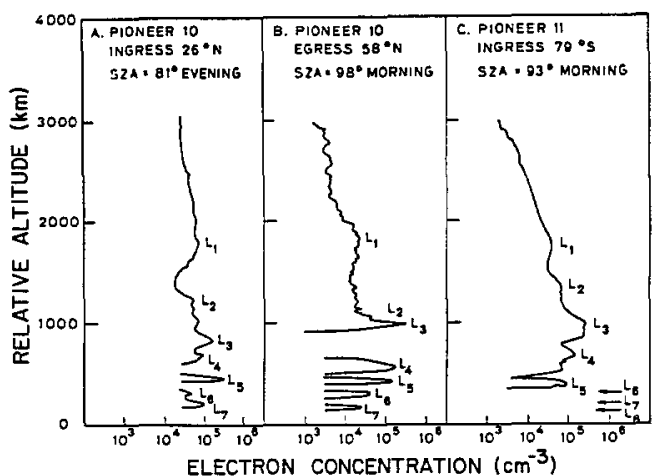

Fig. 7. Pioneer measurements of the ionosphere of Jupiter.

\section{CONCLUSIONS}

Dust needed to explain the stratospheric temperature structure of Jupiter and Saturn might have its origin in the rings. Sulfur and oxygen ions from the Io-plasma torus are most likely responsible for delivering the power needed to drive the aurora at Jupiter, heating of the exosphere, and for providing a sink to the major ions in the high latitudes. Metallic ions of the Io-torus can explain the sporadic E-type layers in the Jovian ionosphere. Water from Saturn's rings might be responsible for suppressing the electron concentration in Saturn's ionosphere. A competing process in most these situations is meteoritic influx. Only a complete spatial mapping - from source to sink - of the materials can unequivocally establish the identity of the source and the importance of extraplanetary material in planetary atmospheres.

\section{ACKNOWLEDGEMENTS}

This research was supported by grants from NASA Planetary Atmospheres Program and NASA Voyager Project.

REEERENCES

1. S.K. Atreya, T.M. Donahue, and W.R. Kuhn, The distribution of ammonia and its photochemical products on Jupiter, Icarus 31,348 (1977)

2. G. Orton and J. Appleby, Temperature structures and infrared derived properties of the atmospheres of Uranus and Neptune, in: Uranus and Neptune, ed. J.T. Bergstralh, NASA $\mathrm{CP} \times \mathrm{xxxx}(1984)$

3. S.K. Atreya, Aeronomy, in: Uranus and Neptune, ed. J.T. Bergstralh, NASA CP $\underline{x \times x x}$ (1984)

4. S.K. Atreya, T.M. Donahue, and W.R. Kuhn, Evolution of a nitrogen atmosphere on Titan, Science 201, 611 (1978)

5. S.K. Atreya, T.M. Donahue, and M.C. Festou, Jupiter: structure and composition of the upper atmosphere, Astrophys. J. Lett. 247, 43 (1981)

6. M.C. Festou and S.K. Atreya, Voyager ultraviolet stellar occultation measurements of the composition and themal profiles of the Saturnian upper atmosphere, Geophys. Res. Lett. 9, 1147 (1982)

7. G.R. Smith, D.E. Shemansky, J.B. Holberg, A.L. Broadfoot, B.R. Sandel, J.C. McConne1 l, Saturn's upper atmosphere from the Voyager 2 EUV solar and stel lar occultation, J. Geophys. Res. 88, 8667 (1983)

8. D.E. Shemansky, private communication (1983)

9. F. Bagenal, and J.D. Sullivan, Direct plasma measurements in the Io torus and inner magnetosphere of Jupiter, J. Geophys. Res. 86, 8447 (1981)

10. D.E. Shemansky, Mass loading and the diffusion-loss rates of the Io plasma torus, Astrophys. J. 242,1266 (1980)

11. N. Gehrels, and E.C. Stone, Energetic oxygen and sulfur ions in the Jovian 
magnetosphere and their contribution to the auroral excitation, J. Geophys. Res. 88 , 5537 (1983)

12. R. Beer, and F.W. Taylor, The abundance of carbon monoxide in Jupiter, Astrophys. J. 221, $1100(1978)$

13. H.A. Larson, U. Fink, and R.R. Treffers, Evidence for Co in Jupiter's atmosphere from airborne spectroscopic observations at 5 microns, Astrophys. J. 219, 1084 (1978)

14. R.G. Prinn, and S.S. Barshay, Carbon monoxide on Jupiter and implications for atmospheric convection, Science 198, 1031 (1977)

15. Science, Mission to Jupiter and its satellites, 204, pp. 945-1øø8 (1979)

16. M.J. Prather, J.A. Logan, and M.B. MCElroy, Carbon monoxide in Jupiter's upper atmosphere: an extraplanetary source, Astrophys. J. 223, 1072 (1978)

17. S.K. Atreya, and T.M. Donahue, The atmosphere and ionosphere of Jupiter, Vistas in Astronomy 25, 315 (1982)

18. S.K. Atreya, J.H. Waite Jr., T.M. Donahue, A.E. Nagy, and J.C. McConnel 1, Theorey measurements and models of the upper atmosphere and ionosphere of Saturn, in: Satum, ed. E. Gehrels, Univ. Arizona Press, Tucson 1984.

19. S.K. Atreya, T.M. Donahue, and J.H. Waite Jr., An interpretation of the Voyager measurement of Jovian electron density profiles, Nature 280, 795 (1979)

20. J.C. McConnel1, J.B. Holberg, G.R. Smith, B. Sandel, D. Shemansky, and A. Broadfoot, A new look at the ionosphere of Jupiter in light of the UVS occultation results, Planet. Space Sci. 30, 151 (1982)

21. J.H. Waite Jr., T.E. Cravens, J.U. Kozyra, A.F. Nagy, S.K. Atreya, and R.H. Chen, Electron precipitation and related aeronomy of the Jovian thermosphere and ionosphere, J. Geophys. Res. 88,6143 (1983)

22. A.L. Broadfoot, B.R. Sandel, D.E. Shemansky, J.B. Holberg, G.R. Smith, D.F. Strobel, J.C. McConnel1, S. Kumar, D.M. Hunten, S.K. Atreya, T.M. Donahue, H.M. Moos, J.L. Bertaux, J.E. Blamont, R.B. Pomphrey, and S. Linick, Extreme ultraviolet observations with Voyager 1 encounter with Saturn, Science 212, 206 (1981)

23. R. Carlson, Photosputtering of ice and hydrogen around Saturn's rings, Nature 283, 461 (1980)

24. W.H. Ip, On the lyman alpha emission from the vicinity of Saturn's rings, Astron. Astrophys. 70, 435 (1978)

25. J.E. Blamont, The atmosphere of the rings of Saturn, in: The Rings of Saturn, NASA SP-343, 1974.

26. G.E. Morfill, H. Fechtig, E. Grün, and C.K. Goertz, Some consequences of meteoroid impacts on Saturn's rings, I carus 55, 439 (1983)

27. A.F. Cheng, L.J. Lanzerotti, and V. Pirrone110, Charged particle sputtering of ice surfaces in Saturn's magnetosphere, J. Geophys. Res. 87, 4567 (1982)

28. M. Shimizu, Strong interaction between the ring system and the ionosphere of Saturn, Proceedings of the 13th Lunar and Planetary Symposia, Institute of Space and Aeronautical 1 Sci., Univ. of Tokyo, July 7-9, 1980.

29. R.H. Chen, Saturn's ionosphere: a corona of ice particles? in: Moon and Planets, D. Reidel, Dordrecht, 1983.

30. J.E.P. Connerney, and J.H. Waite Jr., Wet Model of Saturn's ionosphere: water from rings, Nature submitted (1984)

31. P. Winkelstein, J. Caldwel1, S.J. Kim, M. Combes, G.E. Hunt, and V. Moore, A determination of the composition of the Saturnian stratosphere using the IUE, Icarus 54,309 (1983)

32. S.K. Atreya, T.M. Donahue, and M.B. McElroy, Jupiter's ionosphere: prospects for Pioneer 10, Science 184, 154 (1974) 